\title{
Factors associated with consistent condom use: a cross-sectional survey of two Nigerian universities
}

\author{
Anthony Idowu Ajayi ${ }^{1 *}$ D, Kafayat Olanike Ismail ${ }^{2}$ and Wilson Akpan $^{3}$
}

\begin{abstract}
Background: Consistent condom use is central to the prevention of transmission of human immunodeficiency virus (HIV) and other sexually transmitted diseases (STDs), especially among young adults. This study drew from a cross-sectional survey of two Nigerian universities to determine the level of consistent condom use, explored the determinants of condom use consistency and reasons for inconsistent condom use.

Methods: We adopted a descriptive cross-sectional design, which involves the recruitment of 800 male and female students using stratified random sampling. Adjusted and unadjusted logistic regression models were used to examine the factors associated with consistent condom use among a final sample of 498 students who engaged in sex in the last year preceding the study.

Results: Only $38.6 \%$ of sexually active participants $(n=498)$ used condoms consistently in the previous year. High condom self-efficacy score (AOR: 2.40; 95\% Cl: 1.58-3.64), discussion of HIV/STIs with sexual partner (AOR: 1.91; 95\%Cl: 1.29-2.83), knowing partner's HIV status (AOR: 1.48; 95\% Cl: 1.02-2.16), being students of university located in a high HIV prevalence area (AOR: 2.86; 95\% Cl: 1.92-4.28) and engaging in sex with only steady partner (AOR: 1.74; 95\% Cl: 1.17-2.60) were associated with a higher odds of consistent condom use. Trust, unavailability of condoms, dislike of condoms and a perception that condoms reduced sexual pleasure were the main reasons for inconsistent use of condoms.

Conclusion: The study found a low level of consistent condom use among study participants. Counselling young adults in Nigeria on condom self-efficacy, providing condoms on campuses and encouraging the discussion of sexually transmitted infections with sexual partners are central to improving the level of consistent condom use among Nigerian university students.
\end{abstract}

Keywords: Condoms, Self-efficacy, Consistent condom use, HIV, Drug use, Alcohol use, Nigeria, University students

\section{Background}

Consistent condom use is central to the prevention of transmission of human immunodeficiency virus (HIV) and other sexually transmitted diseases (STDs), especially among young adults $[1,2]$. In sub-Saharan Africa, HIV transmission still constitutes a public health concern, with many adolescents and young adults engaging in unprotected sex and transactional sex and reporting inconsistent condom use [3-10]. Globally, consistent condom use rates range from 4 to $52.4 \%$ among young,

\footnotetext{
* Correspondence: ajayianthony@gmail.com; aajayi@aphrc.org

'Population Dynamics and Reproductive Health Unit, African Population and Health Research Center, APHRC Campus, Off Kirawa Road, Nairobi, Kenya Full list of author information is available at the end of the article
}

sexually active individuals [9-14]. Due to inconsistent condom use, young adults are at a higher risk of acquiring HIV/STIs. Not surprisingly, young adults account for over $50 \%$ of new HIV transmission [15-17]. Studies have also shown that young women are particularly susceptible to HIV acquisition due to social, cultural, economic and structural risk factors that predispose them to engage in risky sexual behaviour [18-20]. This calls for creative strategies to increase the rate of consistent condom use among young people. We defined consistent condom use in this study as the use of condoms at every sexual encounter in the last year.

Even though the prevalence of HIV is relatively low (3.2\%) in Nigeria [21], this low prevalence translates into a

(c) The Author(s). 2019 Open Access This article is distributed under the terms of the Creative Commons Attribution 4.0 International License (http://creativecommons.org/licenses/by/4.0/), which permits unrestricted use, distribution, and 
large number of people living with HIV given the country's large population. The country has the second-largest number of people living with HIV, after South Africa [21]. Although there are no nationally representative data on the prevalence of sexually transmitted diseases, the available evidence (mostly hospital-based studies) shows that the prevalence of STDs is high (14-18.8\%) in Nigeria, especially among young people [22-27]. A study conducted in southeast Nigeria shows that the prevalence of STIs among females was as high as 17\%, with age group 17-19 years more likely to have any type of STI infections (44\%) [28]. What is more worrisome is that many young people are unlikely to seek care or seek care at informal sources, with males commonly seeking care from traditional healers [22-27].

Reasons for inconsistent condom use are well documented. These include low perceived sexual satisfaction derived from the use of condoms, low perceived personal risk of STDs, condom fatigue, having a steady sexual partner, and low condom self-efficacy [11-13, 29, 30]. Studies have identified self-efficacy as the most important predictor of condom use [13, 31-34]. Bandura [35] coined the term 'self-efficacy' and defines it as a "judgment of one's capability to accomplish a certain level of performance". The term is now in popular use in health behaviour and health promotion research, with condom self-efficacy referring to the belief that an individual would feel constantly confident in his/her ability to use a condom with a sexual partner without feeling embarrassed or rejected. Previous studies have reported that high condom self-efficacy has a strong influence on consistent condom use $[10,12]$. However, this link is unclear among women [12, 36]. On the contrary, females are at a higher risk of inconsistent condom use, and this includes women who might have rated themselves highly in condom use self-efficacy [33].

The reasons young adults engage in unsafe sex practices despite knowledge of their consequences continue to generate scholarly interest. A few studies have examined the factors associated with consistent condom use in the Nigerian context (41-42). Onayade et al. (2008) conclude that younger age, having more than one sexual partner, and ability to refuse sex with a partner who does not want to use condoms was associated with a higher likelihood of consistent condom use among males. While the frequency of sexual intercourse and having more than one sexual partner were associated with a higher likelihood of consistent condom use among females. In contrast, Van Rossem et al. (2001) assert that awareness of the efficacy of condoms in preventing HIV and unwanted pregnancy and concerns about HIV and unwanted pregnancy were associated with a higher probability of consistent use of condoms (42). Overall, factors associated with consistent condom use in Nigeria are poorly understood, as there is a dearth of studies examining the influence of sociodemographic, behavioural and psychosocial factors.

\section{Hypotheses}

Studies examining factors associated with consistent condom use among sexually active young people in Nigeria are scarce. To fully understand factors influencing consistent condom use among adolescents and young adults in the Nigerian context and also based on our review of the existing literature on the topic, we proposed five hypotheses. First, studies have established that condom self-efficacy is associated with consistent condom use $[10,12]$. However, the links between condom self-efficacy and consistent condom use have never been investigated in Nigeria. We expect that individuals who expressed higher condom use self-efficacy are more likely to use condoms consistently. We, therefore, expressed our hypothesis as follows:

\section{Hypothesis 1}

High levels of condom self-efficacy are associated with higher odds of consistent condom use among adolescents and young adults in Nigeria.

Also, knowing one's partner status has been shown to promote HIV testing and safe sex practices [37]. While no studies have examined this effect on consistent condom use, we expect that individuals who know their partner's status to be more likely to use condoms consistently compared to those who do not. This leads us to propose our hypothesis two:

\section{Hypothesis 2}

Knowing one's partner status is associated with higher odds of consistent condom use.

More so, there is evidence that couple communication about HIV/STIs promotes safe sex practices and HIV testing [37]. While there are studies that have examined the rate and correlates of consistent condom use in Nigeria [8, 30, 38-40], no studies have examined whether partner communication about HIV/STIs influences consistent condom use. Given the known effect of couple communication on safe sex practices and HIV testing, we expect that partner communication about HIV/STIs will likely increase the odds for consistent condom use. We expressed our hypothesis as follows:

\section{Hypothesis 3}

Partner communication about HIV/STIs is associated with a higher likelihood of consistent condom use.

Also, given the concentration of programmes to reduce HIV transmission in settings with a disproportionately higher prevalence of HIV in Nigeria, we expect that individuals residing in high HIV prevalence areas to use 
condoms consistently compared to those residing in low prevalence areas, with little or no risk reduction interventions. Considering that this study was conducted in two settings - one, where the prevalence of HIV is high and the other where the prevalence of HIV is low- we assessed whether students from high HIV area are significantly more likely to use condoms consistently compared to those from areas with a low HIV prevalence. Our hypothesis is expressed as follows:

\section{Hypothesis 4}

Students from areas with high HIV prevalence are significantly more likely to use condoms consistently compared to those from areas with a low HIV prevalence.

The finding on the relationship between partner type and consistent condom use is unclear. There is evidence that having sex with only a steady partner is associated with consistent condom use [41]. However, a study also shows that having sex with just a regular partner is associated with inconsistent condom use [39], while another study reported no significant difference [40]. We thus aim to examine the relationship number and type of sexual partners and consistent condom use among mostly unmarried young adults in Nigeria. We expressed our hypothesis as follows:

\section{Hypothesis 5}

Having sex with only one partner is associated with a higher likelihood of consistent condom.

\section{Methods}

\section{Participants and sampling}

The data analysed in this study were part of a more extensive study that sought to examine reproductive health and wellbeing of university students in Nigeria [37]. This cross-sectional study was conducted using a researcheradministered questionnaire at the University of Ilorin and Nasarawa State University, both in North Central Nigeria and with a combined student population of approximately 45,000 . The choice of a federal (national) and a state (provincial) university was purposive. Nasarawa State University was purposively selected due to its location in a state with one of the highest rates of HIV prevalence in Nigeria. The Northcentral region of Nigeria, where this study was conducted, has the highest HIV prevalence rate [21]. It is worth noting that Nasarawa State shares boundaries with the Federal Capital Territory, Benue State, Taraba State and Plateau State and that this region has the highest HIV prevalence rate in the country. The prevalence of HIV is low in Ilorin and environs [21]. The University of Ilorin, also located in the North central region of Nigeria, was selected because it is a federally-owned university and one of the highly sought-after universities in Nigeria. As a result, students are admitted to the university from all parts of Nigeria. In terms of tuition fee, both universities are similar; however, the inclusion of both universities further increases the diversity of students included in this study. The detailed methodology has been published elsewhere [42, 43].

A pilot survey (using a semi-structured questionnaire) was conducted among 20 participants. These participants were not included in the main study; instead, their feedback was used to improve the questionnaire. The pilot study took place at the University of Ibadan and was conducted mainly to test the validity and reliability of the instrument.

Sample size estimation was done using a web-based sample size calculator [44]. The appropriate sample size was estimated based on a prevalence of HIV testing uptake of $50 \%$ among the young, educated adults reported in a previous study [45]. For the sample size to detect a $5 \%$ error and representative of each school, a sample size of 384 is required. However, the appropriate sample size representative of each university at a confidence interval of \pm 5 and a $95 \%$ confidence level is 400 participants, after adjusting for possible missing responses. Overall, a pre-tested questionnaire was administered to 800 male and female students selected using a stratified sampling technique. Only 784 respondents returned a completed questionnaire. The survey took place in the two Nigerian universities between March and May 2018. The target population was stratified into both males and females, with proportional samples selected from both strata. For inclusiveness, respondents were also stratified by level of study and faculty of study. A random sample of eligible participants corresponding to the sizes of the strata was recruited.

In a culturally sensitive environment like Nigeria, researching sexual behaviours requires a high degree of privacy, confidentiality and trust. As such, research assistants were taken through a three-day training session, focusing on interview techniques, fieldwork ethics and the importance of earning study participants' trust. The research assistants administered the questionnaire to consenting students in private spaces on campus and students' rooms within the campus (for those who reside on campus residence) and outside of campus (for those who reside in private accommodations not far away from campus). Our preference for the interviewer-administered questionnaire is predicated on the advantage of this method concerning reducing missing responses. It is, however, worth noting that some participant opted to complete their questionnaire alone to which the research assistants permitted. Only undergraduate students of the selected university were included. Visiting students from another university and postgraduate students were excluded from the study. 
The analysis in this study was limited to those who had reported being sexually active in the last year preceding the survey $(n=498)$. The study protocol was reviewed and approved by the Ethical Committees of the University of Fort Hare and Ondo State Ministry of Health. Each participant signed an informed consent form. Overall, the inclusion of participants was voluntary and willful. Respondents were guaranteed utmost confidentiality, privacy and anonymity. The study was conducted in line with the relevant national and institutional committees' rules on human experimentation and with those of the Helsinki Declaration of 1975. Parent permission and assent were obtained for a few students (57) who were 17 years at the time of the study.

\section{Measures}

\section{Consistent condom use}

Consistent condom use was measured using a dichotomised response format and open-ended questions, which allowed for the effective capturing of unstructured responses. To elicit responses regarding the consistency of condom use in recent penetrative sex, we asked sexually active participants four questions, which were: "Did you or your boy/girlfriend use protection regularly in every sexual encounter in the last year?" "If yes, what type of protection?" "In every sexual encounter in the last year, did you always use a condom?" "If not, why not?" Structured responses were provided for their reasons for inconsistent use of condoms. The first and second questions were used for validation purposes. Consistent condom use was derived using only the third questions.

\section{Sexual behaviours}

To measure participants' sexual behaviours, we asked questions with dichotomised responses (yes/no) such as: "Have you ever had sexual intercourse?" "If yes, with how many girls/boys have you ever had sex?" Finally, we also asked questions about the most current or recent sexual behaviours of respondents by asking the following questions: "In the past year, have you engaged in sex with anyone? If yes, with whom did you have sex (category of sexual partner, not name)? "In the last year, with how many girls/boys did you have sex?" Three structured-responses were provided for participants to choose from, namely, "boyfriend/girlfriend only", "casual partner only", "both boyfriend/girlfriend and casual partners".

\section{Condom self-efficacy}

Here, self-efficacy refers to the belief that one can successfully and confidently use condoms consistently and correctly [46]. Condom self-efficacy was measured with 13 questions adapted from a validated tool by Barkley et al. [46]. Self-efficacy was measured by asking respondents to indicate their levels of agreement on a 3-point
Likert scale. Statements such as "I feel confident in my ability to put a condom on myself or my partner", "I feel confident that I could purchase condoms without feeling embarrassed", "I feel confident that I could remember to carry a condom with me, should I need one", "I would not feel confident suggesting using condoms with a new partner because I would be afraid he or she would think I have a sexually transmitted disease" and "If I were to suggest using a condom to a partner, I would feel afraid that he or she would reject me", among others, were used to elicit responses from participants. The responses were codified from 1 ('Agree') to 3 ('Disagree'). The 13item questions yielded a Cronbach's alpha coefficient of 0.811 , which demonstrated that they had a high degree of internal consistency. The 13 questions measuring selfefficacy were scored to yield a maximum score of 39, with higher scores indicating high condom self-efficacy and lower scores indicating lower condom self-efficacy.

\section{Discussion of HIV/STIs with sexual partners}

Discussion of HIV/STIs with sexual partners was assessed by asking the participants: have you discussed HIV/STIs with your sexual partner? Responses were a binary option of "Yes" or "No".

\section{Knowing a partner's HIV status}

Participants were asked to state whether they had knowledge of their partner's HIV status. A binary response (Yes/No) was provided for participants to choose.

\section{Covariates}

Two main levels of covariate were included, which are demographic characteristics (such as age and sex) and substance use (use of substances such as alcohol, drugs and tobacco smoking). Participants reported their sex as either male or female. Participants also stated their age at their last birthday. Age was later categorised into less than 20 years, 20 to 24 years and above and 25 years and over. Alcohol use was assessed with three questions; have you ever drank alcohol? Do you currently drink alcohol? On how many days did you drink alcohol in the past month? Likewise, smoking behaviour was assessed by asking the participant three questions; have you ever smoked any tobacco product (cigarette, pipe, shisha)? Drug use was measured by asking participants to respond to three questions. First was "have you ever used substances/drugs like codeine, cannabis, tramadol etc. for pleasure or to ease tension? Also, we asked whether they currently used drugs like codeine, tramadol, cannabis etc. for pleasure or to ease tension. To assess the frequency of drug use among current users, we asked participants to state how many days in the last month did they use any of these drugs. 


\section{Statistical analysis}

The researchers used Statistical Package for Social Sciences (SPSS, version 24) to carry out descriptive statistical analyses on all variables. Specifically, mean was calculated for continuous variables and frequencies and percentages for categorical variables. We then used ChiSquare and Fisher exact test to examine the relationship between demographic variables, sexual behaviours, HIV testing, discussion of HIV/STDs, perceived risk of contracting HIV/STDs, condom self-efficacy and consistent condom use.

To test the study hypotheses, three models were fitted. The first, being the baseline model, was used to estimate the independent effect of each main predictor variable on consistent condom use. Model 2 controlled for demographic covariates such as age and sex, while Model 3 included both demographic and substance use covariates as controls. Due to the many hypotheses of the study, adjusted and unadjusted binary logistic regression models were used to determine the main predictors of consistent condom use. There was collinearity between 'currently smoke' and 'drug use' thus; currently smoke was not included in the adjusted model. The analysis was done at a $95 \%$ confidence level, and an alpha value of less than 0.05 was deemed statistically significant. List-wise deletion of cases with missing responses (those not sexually active in the previous year) led to only 498 participants being involved in the logistic regression.

\section{Results}

\section{Descriptive results}

As stated above, the analysis was based on the 498 participants who reported being sexually active in the past year. The median age of study participants was 22 years. Most of the participants were below 25 years of age (71.9\%), resided in off-campus residences $(82.3 \%)$ and shared their rooms with at least one person (66.5\%). Just over half of them had ever taken an HIV test (Table 1). The minimum and maximum condom self-efficacy scores were 13 and 39, respectively. The median score was 29. The mean score was $28.96(\mathrm{SD} \pm 5.97)$. The mean score for males and females were $30.31(\mathrm{SD} \pm 5.69)$ and 27.48 ( $\mathrm{SD} \pm 6.22$ ), respectively. Male students had a significantly higher condom self-efficacy score compared to female students (Mean difference $=2.58 ; \mathrm{CI}=1.53$ 3.64). For further analysis, we dichotomised the condom self-efficacy scores into low and high scores, with a score of 27-39 considered high and a score below 27 considered low. The cutoff score of 27, considered to be high condom self-efficacy score, is based on the fact that such participant must have responded affirmatively to 9 out of the 13 questions. In other words, such participants have a score of $70 \%$. Over $66 \%$ of the participants were
Table 1 Demographic characteristics of sexually active participants

\begin{tabular}{lll}
\hline Variables & Frequency $(N=498)$ & Percentage \\
\hline Sex & 263 & 52.8 \\
Male & 235 & 47.2 \\
Female & & \\
Age Category & 94 & 18.9 \\
Less than 20 & 264 & 53.0 \\
20-24 & 140 & 28.1 \\
Above 24 & & \\
Years in the university & 113 & 22.7 \\
First & 123 & 24.7 \\
Second & 107 & 21.5 \\
Third & 115 & 23.1 \\
Fourth & 28 & 5.6 \\
Fifth & 12 & 2.4 \\
Sixth & & \\
Residence & 88 & 17.7 \\
Campus residence & 410 & 82.3 \\
Off-campus residence & 188 & 37.8 \\
Current alcohol users & 106 & 21.3 \\
Current smokers & 120 & 24.1 \\
Current drug users & & \\
\hline
\end{tabular}

in the high condom self-efficacy category, with a significant sex variation (male $74.6 \%$ vs female $56.5 \%$ ). Less than half of the students (42.8\%) knew their partner's HIV status. There was no significant difference between sex and knowing one's partner HIV status (Additional file 1: Table S1). Only $42 \%$ of the students had discussed HIV/STIs with their sexual partners, with no significant sex variation.

Over half $(56.1 \%)$ of the 498 had had sex with only their girl/boyfriends, $20.5 \%$ with casual partners only, $3.7 \%$ with commercial sex workers only and $19.7 \%$ with both girl/boyfriends, casual partners and commercial sex workers. The median number of sexual partners was 2 . The minimum and the maximum number of sexual partners in the previous year were 1 and 15, respectively.

As shown in Additional file 1: Table S1, only 38.6\% (95\% CI: $34.3-43.0 \%$ ) of sexually active students used condoms consistently in the previous year. A higher proportion of males $(41.8 \%$ CI $35.8-48.0 \%)$ compared to females $(34.9 \%$ CI $28.8-41.4 \%)$ affirmed that they consistently used condoms in the past year.

\section{Multivariable analysis}

The results of our hypotheses on the relationship between condom self-efficacy, knowing one's partner HIV status, partner communication about HIV/STIs, number 
of sexual partners and location of residence and consistent condom use are presented in Table 2.

To test hypothesis 1 , which examined the relationship between condom self-efficacy and condom use, we fitted three models. The first is the baseline model that estimated the independent net effect of condom self-efficacy on consistent condom use. The second model controlled for demographic characteristics such as age and sex. The third model added both demographic and substance use covariates. The results indicate that condom self-efficacy is positively associated with consistent condom use. The direction and magnitude of effect remain even after adding the demographic and substance use covariates, as shown in model three. Overall, the results indicate that high condom self-efficacy is associated with a higher likelihood of consistent condom use.

On the relationship between consistent condom use and knowing one's partner status, our hypothesis two, we fitted three models and control for demographic and behavioural covariates. The analysis reveals that knowing one's sexual partner's HIV status increases the odds of consistent condom use. The direction and magnitude of effect persist after controlling for demographic and behavioural covariates. Our finding on the third hypothesis shows that discussion of HIV/STIs with a sexual partner is associated with a higher likelihood of consistent condom use. The magnitude and direction of effect remain after controlling for demographic and substance use covariates.
We likewise fitted three models to understand the relationship between residing in a high HIV prevalence area compared to residing in a low HIV prevalence area. The results show that students studying in a high HIV prevalence area were about three times more likely to consistently use condoms compared to those in a low HIV prevalent area. Overall the finding is robust as evident in model three results.

Our last hypothesis focused on the association between relationship types and consistent condom use. We found that students in a steady relationship or who had sex with only their boyfriend/girlfriend had a higher odds of consistent condom use compared with those who had sex with both their girlfriend/boyfriend and casual partners.

We also examined the main predictors of consistent condom use by including all the main independent variables, and the demographic and substance use covariates in the adjusted binary logistic regression model (Table 3). After adjusting for confounding variable (smoking), only condom self-efficacy, schooling in a high HIV prevalence area, male sex, and having only one sexual partner in the last 1 year were significantly associated with consistent condom use.

\section{Reasons for inconsistent condom use}

Finally, we probed the reasons for inconsistent condom use, and as shown in Table 4, trust, unavailability of condoms, dislike of condoms and a perception that condoms reduce

Table 2 Binary logistic regression models showing relationship between self-efficacy, discussion of HIV/STIs with partner, knowing partners HIV status, schooling in high HIV prevalence area, types of sexual partners and consistent condom use

\begin{tabular}{|c|c|c|c|}
\hline \multirow[t]{2}{*}{ Variables } & Model 1 & Model 2 & Model 3 \\
\hline & UOR $(95 \% \mathrm{Cl})$ & UOR $(95 \% \mathrm{Cl})$ & UOR $(95 \% \mathrm{Cl})$ \\
\hline \multicolumn{4}{|l|}{ Condom self-efficacy } \\
\hline High self-efficacy score $\geq 27$ & $2.45(1.63-3.68)^{* * *}$ & $2.40(1.59-3.64)^{*}$ & $2.40(1.58-3.64)^{* * *}$ \\
\hline Low self-efficacy score $<27$ & 1 & 1 & \\
\hline \multicolumn{4}{|l|}{ Discussed HIV/STDs with sexual partner } \\
\hline Yes & $1.90(1.31-2.74)^{*}$ & $2.03(1.38-2.98)^{* * *}$ & $1.91(1.29-2.83)^{*}$ \\
\hline No & 1 & 1 & 1 \\
\hline \multicolumn{4}{|l|}{ Know sexual partner HIV status } \\
\hline Yes & $1.51(1.05-2.17)^{*}$ & $1.56(1.08-2.26)^{*}$ & $1.48(1.02-2.16)^{*}$ \\
\hline No & 1 & 1 & 1 \\
\hline \multicolumn{4}{|l|}{ University location } \\
\hline Located in high HIV prevalence area & $2.84(1.95-4.13)^{* * *}$ & $3.04(2.07-4.48)^{* * * *}$ & $2.86(1.92-4.28)^{* * *}$ \\
\hline Located in low HIV prevalence area & 1 & 1 & 1 \\
\hline \multicolumn{4}{|l|}{ Type of with sexual partner/s in last year preceding the survey } \\
\hline Main partner only (Boyfriend/girlfriend) & $1.68(1.16-2.43)^{*}$ & $1.82(1.24-2.67)^{*}$ & $1.74(1.17-2.60)^{*}$ \\
\hline Boyfriend/girlfriend, casual partner and commercial sex workers & 1 & 1 & 1 \\
\hline
\end{tabular}

Model 1- contains no covariates

Model 2- controlled for demographic characteristics

Model - controlled for demographic characteristics and established risk factors for risky sexual behaviour such as alcohol and drug use

${ }^{*} P$-value $<0.05,{ }^{* * *} P$-value $<0.001$, UOR unadjusted odds ratio, AOR adjusted odds ratio, $C l$ confidence interval 
Table 3 Adjusted and unadjusted logistic regression analysis showing predictors of consistent condom use

\begin{tabular}{|c|c|c|}
\hline Variables & UOR $(95 \% \mathrm{Cl})$ & AOR $(95 \% \mathrm{Cl})$ \\
\hline \multicolumn{3}{|l|}{ Self-efficacy } \\
\hline High self-efficacy score $\geq 27$ & $2.45(1.63-3.68)^{* * *}$ & $1.86(1.19-2.91)^{*}$ \\
\hline Low self-efficacy score $<27$ & 1 & 1 \\
\hline \multicolumn{3}{|l|}{ University location } \\
\hline $\begin{array}{l}\text { Located in a high HIV } \\
\text { prevalence area }\end{array}$ & $2.84(1.95-4.13)^{* * *}$ & $2.11(1.34-3.32)^{*}$ \\
\hline $\begin{array}{l}\text { Located in a low HIV } \\
\text { prevalence area }\end{array}$ & 1 & 1 \\
\hline \multicolumn{3}{|l|}{$\begin{array}{l}\text { Discussed HIV/STDs with } \\
\text { sexual partner }\end{array}$} \\
\hline Yes & $1.90(1.31-2.74)^{*}$ & $1.37(0.85-2.24)$ \\
\hline No & 1 & 1 \\
\hline \multicolumn{3}{|l|}{ Know partner's HIV status } \\
\hline Yes & $1.51(1.05-2.17)^{*}$ & $1.04(0.65-1.65)$ \\
\hline No & 1 & 1 \\
\hline \multicolumn{3}{|l|}{$\begin{array}{l}\text { Type of with sexual partner/s in } \\
\text { last year preceding the survey }\end{array}$} \\
\hline Boyfriend/girlfriend only & $1.68(1.16-2.43)^{*}$ & $0.86(0.51-1.42)$ \\
\hline $\begin{array}{l}\text { Boyfriend/girlfriend, casual partner } \\
\text { and commercial sex workers }\end{array}$ & 1 & 1 \\
\hline \multicolumn{3}{|c|}{ Number of sexual partners in the last year } \\
\hline Only one sexual partner & $2.08(1.44-3.0)^{* * *}$ & $1.99(1.24-3.19)^{*}$ \\
\hline More one sexual partners & 1 & 1 \\
\hline \multicolumn{3}{|l|}{ Age category } \\
\hline Less than 20 years & $0.92(0.54-1.57)$ & $1.54(0.83-2.85)$ \\
\hline $20-24$ years & $0.97(0.64-1.48)$ & $1.09(0.70-1.71)$ \\
\hline Above 24 years & 1 & 1 \\
\hline \multicolumn{3}{|l|}{ Sex } \\
\hline Male & $1.34(0.93-1.93)$ & $1.53(1.01-2.32)^{*}$ \\
\hline Female & 1 & 1 \\
\hline \multicolumn{3}{|l|}{ Current alcohol users } \\
\hline Yes & $0.95(0.65-1.38)$ & $1.30(0.81-2.10)$ \\
\hline No & 1 & 1 \\
\hline \multicolumn{3}{|l|}{ Currently use drug } \\
\hline Yes & $0.58(0.37-0.90)^{*}$ & $0.77(0.44-1.33)$ \\
\hline No & 1 & 1 \\
\hline
\end{tabular}

${ }^{*} P$-value $<0.05,{ }^{* * *} P$-value $<0.001$

Table 4 Reasons for inconsistent condom use

\begin{tabular}{lll}
\hline Reasons & Frequency $(n=291)$ & Percent \\
\hline I trust my partner & 79 & 27.1 \\
Condom reduces fun & 75 & 25.8 \\
I don't like condoms & 64 & 22.0 \\
I cannot afford it & 3 & 1.0 \\
There was no condom & 70 & 24.1 \\
available when I need to use it & & \\
\hline
\end{tabular}


sexual pleasure were the main reasons for inconsistent use of condoms among the study participants.

\section{Discussion}

This study determined the rate of consistent condom use, explored the determinants of condom use consistency and explored reasons for inconsistent condom use in a sample of young men and women enrolled at two Nigerian universities. Our analysis revealed that only $38.6 \%$ of the students consistently used condoms in the previous year. The level of condom use consistency reported in our study is higher than those reported in previous studies with similar demographics in Nigeria. For instance, a lower rate of condom use consistency (24.2\%) was reported in a study conducted in a tertiary institution in Ile-Ife, Southwestern, Nigeria [39]. An even lower rate of consistent condom use (15\% for men and $4 \%$ for women) was reported among fresh graduates of tertiary institutions who are on migration for compulsory national assignment in Ibadan, Nigeria [30]. However, a higher rate of condom use consistency (48.8\%) was reported among HIV positive individuals attending an HIV treatment centre in Lagos, Nigeria [38]. The rate of consistent condom use reported in this study is within the range reported among undergraduate students in previous studies $(29.6-52.4 \%)[9,33,47]$.

The findings of the present study revealed that the level of consistent condom use is low among Nigerian university students. Considering that many of these students had multiple sexual partners in the year preceding the study, inconsistent condom use among Nigerian students is worrisome and clearly indicates a need for a public health intervention. The findings thus have broad implications for the sexual health of Nigerian university students. Inconsistent use of condoms, especially with multiple sexual partners, is a risky sexual behaviour with dire consequences. Beyond the risk of HIV and other STI transmission, students could also be faced with associated unplanned pregnancies and unsafe abortions [17, 48, 49]. Counselling students on consistent condom use, including assessment of self-efficacy towards condom use, would be an important step towards addressing these public health issues in the study setting. This finding further lays credence to studies that have shown that unprotected sex is common among Nigerian students [3, 50, 51].

Consistent with previous studies $[10,13,41]$ our results strongly support the hypothesis that condom self-efficacy is associated with a higher likelihood of consistent condom use. Despite controlling for relevant covariates, the magnitude and direction of effect of condom self-efficacy on consistent condom use persist. Individuals with high condom self-efficacy scores were approximately twice as likely to report consistent condom use compared to those with low condom self-efficacy scores. Although our study is cross-sectional, nonetheless the finding suggests that intervention that targets increasing condom self-efficacy among students could be useful in increasing the rate of consistent condom use in the study setting. Social marketing campaigns on campuses and motivational counselling at campus-based clinics are cheap interventions that could be implemented on campuses across the country.

One interesting finding of this study is that discussion of HIV/STDs with sexual partners and knowing one's partner HIV status were associated with consistent condom use. This suggests that encouraging youths to have HIV/STD conversations with sexual partners could be a useful intervention for increasing the level of consistent condom use. In other words, the discussion on the risk of contracting HIV/STDs could promote the consistent use of condoms. A study conducted in South Africa found that individuals who discussed HIV/STDs with their sexual partners were more likely to use condoms compared to respondents who had not [52].

This study also established that students studying in a high HIV prevalence area had higher odds of consistent condom use. This finding is expected, considering that interventions aimed at reducing HIV transmission are concentrated in these areas. It is plausible that people are more aware of their risk of contracting HIV and ways of preventing HIV transmission. Also, in areas with a concentration of HIV risk-reduction interventions, condoms are more likely to be supplied freely. Considering that this study also found that lack of condom availability is among the reasons for inconsistent condom use, one could, therefore, infer that people are more likely to use condoms in areas targeted with risk reduction interventions because of condom availability. This finding may also be construed as evidence of the effectiveness of the HIV risk reduction interventions targeting areas with high HIV prevalence in Nigeria.

This study also shows that having just one sexual partner or only the partner in the past year is associated with a higher likelihood of consistent condom use. This finding corroborates a study [41] that found an association between consistent condom use and having just one partner among rural young women in South Africa. However, one Nigerian study reported that women with multiple partners were more likely to consistently use condoms [39] while having multiple sexual partners did not significantly affect consistent condom use among men [40]. In one Kenyan study, men mostly used condoms when having sex with commercial sex workers and were less likely to use condoms when having sexual intercourse with regular partners and casual partners [53]. It could be that individuals who maintain a steady relationship are more likely to engage in protective sexual behaviour, including consistent condom use. In other 
words, those that engage in sex with both casual partners and main partners are more likely to engage in risky sexual behaviour, including inconsistent condom use compared to those that did not. It is also possible that those who engaged in sex with both casual partners and steady partner would use condoms with casual partners and fail to use condoms with a steady partner.

Trust, unavailability of condoms, dislike of condoms and perceptions that condoms reduce sexual pleasure were the main reasons for inconsistent use of condoms among students - all of which corroborated previous studies $[11-13,29,30]$. Also, a previous study conducted among Nigerian university students has shown that despite being aware of the risks associated with unprotected sex, Nigerian students engage in risky sexual behaviour due to perceptions that condoms reduce sexual pleasure and the often unfounded belief that their partners are free of any sexually transmitted diseases [3]. This study contributes to the extant literature by adding that, unavailability of condoms at the time they are needed, as well as a personal dislike of condoms, are among the reasons for inconsistent condom use among Nigerian university students. Provisioning of condoms on campuses would be an important intervention to address the unavailability of condoms and could increase the level of consistent condom use among university students. Given that this intervention is cheap and has been effectively implemented in other settings such as South African campuses, government and non-governmental agencies should prioritise this intervention. Also, it is worth noting that the use of oral pills, implants, injectables and IUD is very low among young people in Nigeria, and this is as a result of several misconceptions regarding these contraceptive methods [54]. In this study, for example, no student reported the use of these contraceptive methods. Young people in Nigeria believe women that have no children should not use hormonal contraceptive methods and often considered there use to lead to future infertility $[50,51]$.

\section{Limitations}

Although this study elevates the discourse on consistent condom use, the findings must be generalised with caution. This study was conducted among young adults with higher education levels compared to the general population, thus limiting the generalisability of its findings to the overall Nigerian population. Also, the use of a cross-sectional design in this study indicates that the association between condom self-efficacy and consistent condom use does not infer causation. Also, due to the reliance on selfreporting of consistent condom use, one cannot exclude the possibility of under-reporting of inconsistent condom use as a result of social desirability bias. It is also important to note that people with multiple partners may not use condoms with their regular partner but use condoms with their casual partners.

\section{Conclusion}

This study shows that the level of consistent condom use is low among university students in Nigeria. High condom self-efficacy, type of sexual partner, and having discussed HIV/STDs with sexual partners were significantly associated with consistent condom use. Counselling young adults in Nigeria on condom self-efficacy, and encouraging the discussion of sexually transmitted infections with sexual partners are central to improving the level of consistent condom use among Nigerian university students. Intervention such as the provisioning of condoms to students on campus could help in addressing the unavailability barrier to consistent condom use and increase the level of consistent condom use among Nigerian university students. Besides intervention to improve condom self-efficacy, regular HIV testing and awareness and use of pre-exposure prophylaxis are among effective intervention for prevention of HIV and STIs, especially for individuals who find condoms to be inappropriate in their relationship.

\section{Additional file}

Additional file 1: Table S1. Demographic and behavioural correlates of consistent condom use. Cl-confidence interval (DOCX $17 \mathrm{~kb}$ )

\section{Abbreviations}

HIV: Human immunodeficiency virus; STDs: Sexually transmitted diseases; STIs: Sexually transmitted infections

\section{Acknowledgements}

The authors would like to acknowledge the University of Fort Hare and Govan Mbeki Research Institute for granting AIA a postdoctoral fellowship position during which he completed the empirical aspects of this study. We also express our gratitude to our research assistants, Ojo Oluwayomi and Abioye Olumide Abdulazeez, for their immense contributions towards the completion of the data collection.

\section{Authors' contributions}

AIA conceptualised and designed the study. $\mathrm{KOI}$ and WA contributed to the implementation and the drafting and development of the manuscript. AIA analysed the data and contributed to the drafting of the manuscript. All authors read the final version of the manuscript.

\section{Funding}

The authors did not receive any funding for this work.

\section{Availability of data and materials}

All relevant data generated during this study will be made available by the corresponding author upon reasonable request.

Ethics approval and consent to participate

The University of Fort Hare and Ondo State Ministry of Health's Ethical Review Committees approved the study protocol. All study participants gave written consent to indicate their voluntary participation.

Consent for publication

Not applicable 


\section{Competing interests}

The first author is an associate editor with BMC Public Health. Other authors declare that they have no competing interests.

\section{Author details}

'Population Dynamics and Reproductive Health Unit, African Population and Health Research Center, APHRC Campus, Off Kirawa Road, Nairobi, Kenya. ${ }^{2}$ Department of Sociology, Faculty of the Social Sciences, University of Ilorin, Ilorin, Nigeria. ${ }^{3}$ Research and Innovation, Walter Sisulu University, Nelson Mandela Drive, Mthatha, South Africa.

\section{Received: 20 August 2018 Accepted: 25 August 2019} Published online: 02 September 2019

\section{References}

1. Ahmed S, Lutalo T, Wawer M, Serwadda D, Sewankambo NK, Nalugoda F, Makumbi F, Wabwire-Mangen F, Kiwanuka N, Kigozi G. HIV incidence and sexually transmitted disease prevalence associated with condom use: a population study in Rakai, Uganda. Aids. 2001;15(16):2171-9.

2. Nielson CM, Harris RB, Nyitray AG, Dunne EF, Stone KM, Giuliano AR. Consistent condom use is associated with lower prevalence of human papillomavirus infection in men. J Infect Dis. 2010;202(3):445-51.

3. Ajayi Al, Nwokocha EE, Akpan W, Adeniyi OV, Goon DT. "It's sweet without condom": Understanding Risky Sexual Behaviour Among Nigerian Female University Students. Online J Health Allied Scs. 2017;16(4):9.

4. Brown JL, Vanable PA. Alcohol use, partner type, and risky sexual behavior among college students: findings from an event-level study. Addict Behav. 2007;32(12):2940-52.

5. Imaledo JA, Peter-Kio OB, Asuquo EO. Pattern of risky sexual behavior and associated factors among undergraduate students of the University of Port Harcourt, Rivers State, Nigeria. Pan Afr Med J. 2012;12(1):97.

6. Noubiap JJN, Nansseu JRN, Ndoula ST, Wang B, Jingi AM, Bigna JJR, Aminde LN, Youmbi RA, Fokom-Domgue J. Prevalence and correlates of HIV-risky sexual behaviors among students attending the medical and social welfare Center of the University of Maroua, Cameroon. BMC Res Notes. 2015;8(1):635.

7. Ritchwood TD, Ford H, DeCoster J, Sutton M, Lochman JE. Risky sexual behavior and substance use among adolescents: a meta-analysis. Child Youth Serv Rev. 2015;52:74-88.

8. Oladosu M, Ladipo AO. Consistent condom use among sex workers in Nigeria. PSI/Europe. 2001;(39). Available at: https://core.ac.uk/download/pdf/ 83592774.pdf.

9. Tarkang EE. Factors associated with consistent condom use among senior secondary school female learners in Mbonge subdivision of rural Cameroon. J AIDS HIV Res. 2012;5(6):214-23.

10. Wong WCW, Cheng S, Miu HYH, Ong JJ, Chen J, Loper KA. Contextual factors associated with consistent condom use and condom self-efficacy amongst African asylum seekers and refugees in Hong Kong. Infect Dis Health. 2017;23:23-32

11. Bryan AE, Norris J, Abdallah DA, Zawacki T, Morrison DM, George WH, Davis KC, Danube CL, Stappenbeck CA. Condom-insistence conflict in Women's alcohol-involved sexual encounters with a new male partner. Psychol Women Q. 2017:41(1):100-13.

12. Nesoff ED, Dunkle K, Lang D. The impact of condom use negotiation selfefficacy and partnership patterns on consistent condom use among college-educated women. Health Educ Behav. 2016;43(1):61-7.

13. Roy KP, Mahapatra B, Bhanot A, Kapoor A, Narayanan SS. Psychosocial correlates of HIV-related sexual risk factors among male clients in southern India. Int J Psychol Behav Sci. 2012;2(6):245-54.

14. Zhao R, Wang B, Fang X, Li X, Stanton B. Condom use and self-efficacy among female sex workers with steady partners in China. AIDS Care. 2008;20(7):782-90.

15. The Joint United Nations Program on HIV/AIDS: When women lead change happens: Women advancing the end of AIDS; 2017.

16. WHO, UNAIDS, UNICEF. Global report: UNAIDS report on the global AIDS epidemic 2013. Geneva: UNAIDS; 2013. p. 3-5.

17. Newman L, Rowley J, Vander Hoorn S, Wijesooriya NS, Unemo M, Low N, Stevens G, Gottlieb S, Kiarie J, Temmerman M. Global estimates of the prevalence and incidence of four curable sexually transmitted infections in 2012 based on systematic review and global reporting. PLoS One. 2015: 10(12):e0143304.
18. Gillespie S, Kadiyala S, Greener R. Is poverty or wealth driving HIV transmission? Aids. 2007;21:S5-S16.

19. Madise N, Zulu E, Ciera J. Is poverty a driver for risky sexual behaviour? Evidence from national surveys of adolescents in four African countries: original research article. Afr J Reprod Health. 2007;11(3):83-98.

20. Weiser SD, Leiter K, Bangsberg DR, Butler LM, Percy-de Korte F, Hlanze Z, Phaladze N, lacopino V, Heisler M. Food insufficiency is associated with high-risk sexual behavior among women in Botswana and Swaziland. PLoS Med. 2007:4(10):1589-97.

21. Awofala AA, Ogundele OE. HIV epidemiology in Nigeria. Saudi J Biol Sci. 2018;25(4):697-703.

22. Mmari KN, Oseni O, Fatusi AO. STI treatment-seeking behaviors among youth in Nigeria: are there gender differences? Int Perspect Sex Reprod Health. 2010;36:72-9.

23. Nwadike VU, Olusanya O, Anaedobe GC, Kalu I, Ojide KC. Patterns of sexually transmitted infections in patients presenting in special treatment clinic in Ibadan south western Nigeria. Pan Afr Med J. 2015;21(1):222.

24. Okonko I, Akinpelu A, Okerentugba P. Prevalence of sexually transmitted infections (STIS) among attendees of AFRH Centre in Ibadan, southwestern Nigeria. Middle East J Sci Res. 2012;11:24-31.

25. Olakolu SS, Abioye-Kuteyi EA, Oyegbade OO. Sexually transmitted infections among patients attending the general practice clinic, Wesley Guild Hospital, Ilesa, Nigeria. S Afr Fam Pract. 2011;53(1):63-70.

26. Olalekan RM, Owobi OE. Assessment of the rate of sexually transmitted diseases in Kubwa FCT Abuja, Nigeria. Science. 2017;5(5):365-76.

27. Osazuwa F, Ifueko O-M. Seroprevalence of sexually transmitted diseases (herpes, chlamydia, and syphilis) in pregnant women in Warri, Nigeria. CHRISMED J Health Res. 2017;4(2):155.

28. Brabin L, Kemp J, Dollimore N, Obunge O, Ikimalo J, Briggs N, Odu N, Hart CA. Reproductive tract infections and abortion among adolescent girls in rural Nigeria. Lancet. 1995;345(8945):300-4.

29. Kwok QM, Chau JP, Holroyd EA. Examining the relationships between condom use self-efficacy and condom use among mainland Chinese sex workers in Hong Kong. J Nurs Sci. 2010;28(2):23-32.

30. Sunmola AM, Olley BO, Oso GE. Predictors of condom use among sexually active persons involved in compulsory national service in Ibadan, Nigeria. Health Educ Res. 2007;22(4):459-72.

31. Downs JS, Ashcraft AM, Murray PJ, Berlan ED, de Bruin WB, Eichner J, Fischhoff B, Leary JM, McCall RB, Miller E. Video intervention to increase perceived self-efficacy for condom use in a randomized controlled trial of female adolescents. J Pediatr Adolesc Gynecol. 2017; 31:291-298.e2.

32. Goodman ML, Harrell MB, Gitari S, Keiser PH, Raimer-Goodman LA. Selfefficacy mediates the association between partner trust and condom usage among females but not males in a Kenyan cohort of orphan and vulnerable youth. Afr J Reprod Health. 2016;20(2):94-103.

33. Mehra D, Östergren P-O, Ekman B, Agardh A. Inconsistent condom use among Ugandan university students from a gender perspective: a crosssectional study. Glob Health Action. 2014;7(1):22942.

34. Xu Y, Chen $X, Y u B$, Joseph $V$, Stanton B. The effects of self-efficacy in bifurcating the relationship of perceived benefit and cost with condom use among adolescents: a cusp catastrophe modeling analysis. J Adolesc. 2017;61:31-9.

35. Bandura A. Self-efficacy: toward a unifying theory of behavioral change. Psychol Rev. 1977;84(2):191.

36. Simpson R. Condom use self-efficacy in the pregnant adolescent population. New Jersey: Rutgers University-Graduate School-Newark; 2014.

37. Ajayi Al, Abioye AO, Adeniyi OV, Akpan W. Concerns about contracting HIV, knowing partners' HIV sero-status and discussion of HIV/STI with sexual partners as determinants of uptake of HIV testing; 2018. p. 1-13.

38. Ayoola OD, Victoria G-OC, Bamidele O, Olufela KO, Oluwatosin SE, Mbaneifo EP, Titilola G, Adagu AR, Ifeanyi OD, Harry O. Pattern, challenges and correlates of condom use among Nigerians living with HIV infection. Asian Pac J Trop Biomed. 2014;4:S198-203.

39. Onayade A, Abiona T, Ugbala C, Alozie G, Adetuyi O. Determinants of consistent condom use among adolescents and young adults attending a tertiary educational institution in Ile-Ife, Nigeria. Niger Postgrad Med J. 2008;15(3):185-91.

40. Van Rossem R, Meekers D, Akinyemi Z. Consistent condom use with different types of partners: evidence from two Nigerian surveys. AIDS Educ Prev. 2001;13(3):252. 
41. Jama Shai N, Jewkes R, Levin J, Dunkle K, Nduna M. Factors associated with consistent condom use among rural young women in South Africa. AIDS Care. 2010;22(11):1379-85.

42. Ajayi Al, Ismail KO, Adeniyi OV, Akpan W. Awareness and use of pre-exposure and postexposure prophylaxes among Nigerian university students: findings from a cross-sectional survey. Medicine. 2018;97(36):e12226.

43. Ajayi Al, Somefun OD. Transactional sex among Nigerian university students: The role of family structure and family support. PloS one. 2019;14(1): e0210349.

44. Kadam P, Bhalerao S. Sample size calculation. Int J Ayurveda Res. 2010;1 (1):55.

45. Ogaji D, Oyeyemi A, Ibrahim I. Awareness, willingness and use of voluntary HIV testing and counseling services by students of a university in southSouth Nigeria. J Commun Med Prim Health Care. 2013;25(2):36-44.

46. Barkley TW Jr, Burns JL. Factor analysis of the condom use self-efficacy scale among multicultural college students. Health Educ Res. 2000;15(4):485-9.

47. Obsa AG, Weldihanes BA. Knowledge and self-efficacy on HIV/AIDS among undergraduate students of Madda Walabu University. Southeast Ethiopia: Global Journal of Human-Social Science Research; 2017.

48. World Health Organization. Unsafe abortion: global and regional estimates of the incidence of unsafe abortion and associated mortality in 2008. Geneva: WHO; 2013.

49. Ajayi Al, Akpan W, Goon DT, Nwokocha EE, Adeniyi OV. Tough love: socio-cultural explanations for deadly abortion choices among Nigerian undergraduate students: health. African J Phys Act Health Sci. 2016;22(Issue-31):711-24.

50. Ajayi Al, Nwokocha EE, Akpan W, Adeniyi OV. Use of non-emergency contraceptive pills and concoctions as emergency contraception among Nigerian University students: results of a qualitative study. BMC Public Health. 2016;16(1):1046.

51. Ajayi Al, Nwokocha EE, Adeniyi OV, Goon D, Akpan W. Unplanned pregnancy-risks and use of emergency contraception: a survey of two Nigerian universities. BMC Health Serv Res. 2017;17(1):382.

52. Conserve DF, Middelkoop K, King G, Bekker L-G. Factors associated with HIV discussion and condom use with sexual Partners in an Underserved Community in South Africa. J Health Care Poor Underserved. 2016;27(1):131.

53. Westercamp N, Mattson CL, Madonia M, Moses S, Agot K, Ndinya-Achola JO, Otieno E, Ouma N, Bailey RC. Determinants of consistent condom use vary by partner type among young men in Kisumu, Kenya: a multi-level data analysis. AIDS Behav. 2010;14(4):949-59.

54. Ajayi Al, Adeniyi OV, W A. Use of traditional and modern contraceptives among childbearing women: findings from a mixed methods study in two southwestern Nigerian states. BMC Public Health. 2018;18(1):604.

\section{Publisher's Note}

Springer Nature remains neutral with regard to jurisdictional claims in published maps and institutional affiliations.

Ready to submit your research? Choose BMC and benefit from:

- fast, convenient online submission

- thorough peer review by experienced researchers in your field

- rapid publication on acceptance

- support for research data, including large and complex data types

- gold Open Access which fosters wider collaboration and increased citations

- maximum visibility for your research: over $100 \mathrm{M}$ website views per year

At $\mathrm{BMC}$, research is always in progress.

Learn more biomedcentral.com/submissions 